\title{
Spectrophotometric Micro-determination of Three Quinolones Antibacterial Drugs in Pure and in Pharmaceutical Dosage Forms by Reactions with Diphenylamine Sulphonate Redox Indicator
}

\author{
M.A. Zayed and Raghda M. Belal \\ Chemistry Department, Faculty of Science, Cairo University, \\ 12613-Giza, Egypt.
}

\begin{abstract}
A RELIABLE, sensitive and efficient new spectrophotometric $A$ methods for the determination of three quinolones, namely Ciprofloxacin (CIP), Norfloxacin (NOR) and Nalidixic acid (NA) have been performed either in pure or in pharmaceutical dosage form. The methods are based on the reaction of the studied drugs with diphenyl amine sulphonate (DPAS) indicator in its oxidized form obtained by indicator titration with potassium dichromate in sulfuric acid medium. Two products form in two concentration ranges of each drug and two mechanisms of reactions are involved. The first reaction mechanism; drugs reduce DPAS oxidant (violet form) and their concentrations are micro-determined at $\lambda \max =545$ $550 \mathrm{~nm}$ for NA, CIP and NOR, respectively. The second mechanism; their concentrations are micro-determined via ion pair which is formed after $30 \min$ (brown form) at $\lambda \max =245,280$, and $285 \mathrm{~nm}$ for NA, CIP and NOR, respectively. The results are validated statistically by $\%$ recovery, SD and RSD values. The robustness and ruggedness of the methods are checked by inter and intra-days tests. The proposed methods are in good agreement with those given by the official methods as confirmed by F- and t- tests.

Keywords: Quinolones , Ciprofloxacin , Norfloxacin , Nalidixic acid , Diphenyl amine sulphonate (DPAS) and Spectrophotometric methods .

4-Quinolones are defined as an important group of synthetic antibacterial compounds with good oral absorption and excellent bioavailability. Nalidixic acid (NA), Ciprofloxacin (CIP), and Norfloxacin (NOR) are antimicrobial agents belonging to 4-Quinolone. 4-Quinolone antibiotics are characterized by their ability to inhibit the replication of DNA gyrase (Topoisomerase) which is essential for the reproduction of bacterial DNA ${ }^{(1)}$. They are commercially available for treatment of a wide range of infections. The fluorinated 4quinolone derivatives have a broad spectrum activity and are more potent invitro than the non-fluorinated ones. The widespread use of this group of drugs has prompted extensive literature on their analysis in dosage forms and
\end{abstract} biological fluids.

*Corresponding author: e-mail: mazayed429@yahoo.com,

Tel: 002-02-22728437, 002-01005776675, Fax: 002-02-35728843. 
<smiles>O=C(O)C1CC(C2CC2)N(C2CC2)CC1C(=O)O</smiles>

CP<smiles>CCn1cc(C(=O)O)c(=O)c2ccc(C)nc21</smiles>

NA<smiles>CCN1CC(C(O)O)C(O)C2CC(N3CCNCC3)C(F)CC21</smiles>

NOR

The United States Pharmacopoeia ${ }^{(2)}$ recommends a non aqueous titration method for the determination of Nalidixic acid, a liquid chromatographic method for determination of Ciprofloxacin and a non-aqueous titrimetric method, with potentiometric detection of the end point for Norfloxacin, in their bulk ; and spectrophotometric or HPLC methods for their dosage forms. Also, the British Pharmacopeia ${ }^{(3)}$ reported similar titrimetric methods for Nalixidic acid, Norfloxacin and Ciprofloxacin in pure forms; and a spectrophotometric method for their dosage forms. Spectrophotometric methods reported for the determination of the studied drugs included oxidative coupling with 3-methyl-2benzo thiazolinone hydrazone hydrochloride (MBTH) and cerium (IV) ammonium sulphate ${ }^{(4)}$; Ion-pair complex formation with xanthenes dyes ${ }^{(5)}$, Cobalt (II) Tetrathiocyanate ${ }^{(6)}$ nickel (II) tetra thiocyanate ${ }^{(7)}$, and Bromocresol Green ${ }^{(8)}$, also charge-transfer complexation with the acid-dye bromocresol green ${ }^{(9)}$ and $\pi$-acceptors such as tetracyanoethylene and Chloranilic acid ${ }^{(10)}$; complexation with iron (III), cupper (II) ions ${ }^{(11,12)}$ or with tris (ophenanthroline) iron (II) and tris(bipyridyl) iron (II) ${ }^{(13)}$. Spectrophotometric study presents the kinetics and degradation pathways of oxidation of the studied drugs by permanganate in alkaline medium ${ }^{(14,15)}$. Derivative Spectrophotometric Analysis ${ }^{(16-18)}$ has been reported. Other methods included Potentiometry ${ }^{(19-22)}$ and the oxidation reaction of Norfloxacin with cerium (IV) ${ }^{(23)}$, Voltammetry ${ }^{(24)}$, Titrimetry ${ }^{(25-27)}$, Atomic Absorption Spectroscopy (AAS) via reaction with metal $^{(28)}$, Fluorimetry ${ }^{(29)}$, UPLC $^{(30)}$, HPLC ${ }^{(31-33)}, \mathrm{GC}^{(34)}$ had been reported for the determination of the studied drugs.

This paper aims chiefly to find simple spectrophotometric methods for the micro-determination of the above mentioned drugs in pure forms and their tablet formulations based on the redox reaction by using DPAS oxidant indicator, and following the reactions through Visible region to their completion at UV region including the studying of the optimum conditions for the reactions to take place. 


\section{Experimental}

\section{Materials and Reagents}

All materials used were of analytical reagent grade and some of them were used as such without any further purification. They included Nalidixic acid provided by Applichem-Germany, Ciprofloxacin (CIP) provided by Unipharma, Egypt, and Norfloxacin (NOR) provided by Egyptian International Pharmaceutical Industries CO. (EIPICO) - Egypt.

Stock solutions of the studied drugs were prepared as $10^{-3} \mathrm{M}$ where CIP was prepared by dissolving the accurately weighed amount of the pure drug, NA was prepared by dissolving the accurately weighed amount of the pure drug in $0.05 \mathrm{M} \mathrm{NaHCO}_{3}$ solution with gentle warming, NOR was prepared by dissolving the accurately weighed amount of the pure drug in $40 \mathrm{ml} \mathrm{NaHCO}_{3}$ solution with heating for $10 \mathrm{~min}$, and finally the volumes were completed to $100 \mathrm{ml}$ measuring flask by distilled water. The solutions were stable for at least two weeks if they had been stored in a cool $\left(<25{ }^{\circ} \mathrm{C}\right)$ and dark place. Sodium Diphenylamine sulphonate (DPAS) supplied from Alpha chemika - India, and was prepared in distilled water as $10^{-3} \mathrm{M}$. Sulfuric acid $\left(\mathrm{H}_{2} \mathrm{SO}_{4}\right)$ was supplied from Merck, and was prepared in distilled water as $2 \mathrm{~N}$. Potassium dichromate $\left(\mathrm{K}_{2} \mathrm{Cr}_{2} \mathrm{O}_{7}\right)$ was supplied from Adwic, and was prepared in distilled water as $0.1 \mathrm{M}$.

Solutions of lower concentration were obtained by accurate dilution of these solutions with distilled water. Ciprofar tablets were obtained from Pharco Pharmaceuticals, Egypt, labeled to contain (500 mg CIP tablet ${ }^{-1}$ ). Nalidram tablets were obtained from Memphis Co. Pharm. and Chemical Ind, Egypt, labeled to contain $\left(500 \mathrm{mg}\right.$ NA tablet $\left.{ }^{-1}\right)$. Norbactin tablets were obtained from CID Pharmaceuticals Co, Egypt, labeled to contain (400 mg NOR tablet ${ }^{-1}$ ).

\section{Apparatus}

Optizen recording UV-Visible spectrophotometer (Model 5u470/pop 127022-00), equipped with $1 \mathrm{~cm}$ matched quartz cells was used for spectrophotometric measurements. Weights measurement was performed by using Radwag wagi Elektroniczne Sensitive analytical balance 0.0001g, Model: AS 220/C/1.Stirring and heating were performed by using ARE Heating Magnetic Stirrer Theromostated Hot Plate, Model: VELP-Europe. Automatic Micropipettes, Model: Accupipette USA, Volume range 100-1000 $\mu \mathrm{L}$ were used to measure the small volumes.

\section{General recommended procedure}

Procedure for drugs in pure form

Solution of DPAS in its oxidized form (Blank) was prepared by its titration in $0.2 \mathrm{~N} \mathrm{H}_{2} \mathrm{SO}_{4}$ against $0.1 \mathrm{M} \mathrm{K}_{2} \mathrm{Cr}_{2} \mathrm{O}_{7}$ till violet color.

Solutions of equimolar amounts $\left(4 \times 10^{-4} \mathrm{M}\right)$ were prepared between the studied drugs and DPAS indictor in its oxidized form and spectrophotometric 
determinations were carried out at Vis. region (instantaneously) and after dilution to $\left(4 \mathrm{X} 10^{-5} \mathrm{M}\right)$ at $\mathrm{UV}$ - region (after $\left.30 \mathrm{~min}\right)$.

\section{Procedure for dosage forms}

Each ten tablets of Ciprofar (500 mg/tablet), Nalidram (500 mg/tablet), and Norbactin $(400 \mathrm{mg} / \mathrm{tablet})$ were weighed and powdered well. Equivalent amount of powder to one tablet of the drugs was weighed, and dissolved in sufficient amount of $0.05 \mathrm{M} \mathrm{NaHCO}_{3}$ solution, with gentle warming. The resulting solutions were shacked well. The solutions of the drugs were transferred into $100 \mathrm{ml}$ volumetric flask and the volume completed to the mark with distilled water. Analysis was completed as previously mentioned under the general procedure to measure in both Vis region and UV one. The nominal content of the tablets was thus calculated either from a previously plotted calibration graph or using the regression equation.

\section{Result and Discussion}

Usually DPAS is used as an indicator to follow redox reaction between oxidant like $\mathrm{K}_{2} \mathrm{Cr}_{2} \mathrm{O}_{7}$ and reducing agents like ferrous in sulfuric acid medium aiming to detect end-point in volumetric titrations ${ }^{(35)}$. In this thesis DPAS is used as an oxidant in its oxidized form and as spectrophotometric self-indicator, for a first time, to follow its reaction with fluoroquinolones such as Ciprofloxacin (CIP), Norfloxacin (NOR) and Nalidixic acid (NA) Spectrophotometrically.

Violet form and selection of suitable wavelengths

In order to prepare DPAS in its oxidized form it required titration of the indicator with $\mathrm{K}_{2} \mathrm{Cr}_{2} \mathrm{O}_{7}$ in sulfuric acid medium till violet color. The obtained results are given in Fig. 1. it has a $\lambda_{\max }=560 \mathrm{~nm}$ (curve1). It is shifted to lower wavelengths on reaction with the cited drugs at the same conditions within 10 min (curves 2, 3, 4).

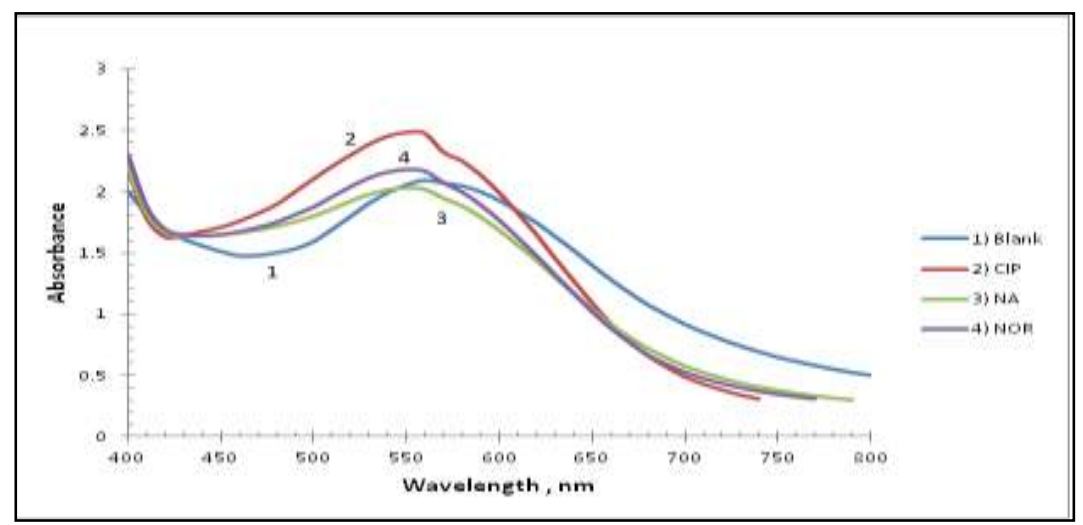

Fig. 1. Visible spectra of $4 \times 10^{-4} \mathrm{M}$ DPAS oxidant indicator as a blank (curve 1) and $4 \mathrm{X10}^{-4} \mathrm{M}$ mixture of DPAS oxidant, with drug CIP, NA or NOR (curves 2-4) at normal temp.

Egypt. J. Chem. 58, No. 3 (2015) 
These results indicate that, the reaction between DPAS in its oxidized form and the cited drugs in its reduced form can be followed at $550 \mathrm{~nm}$ for both CIP and NOR while at $545 \mathrm{~nm}$ for NA due to the proposed redox reaction mechanism presented in Scheme 1, taking Nalidixic acid as an example. In this scheme the NA oxidized to 7-carboxinaldixic acid and DPAS changed to its reduced form coming from reduction of quinoid structure via reaction with the drug.

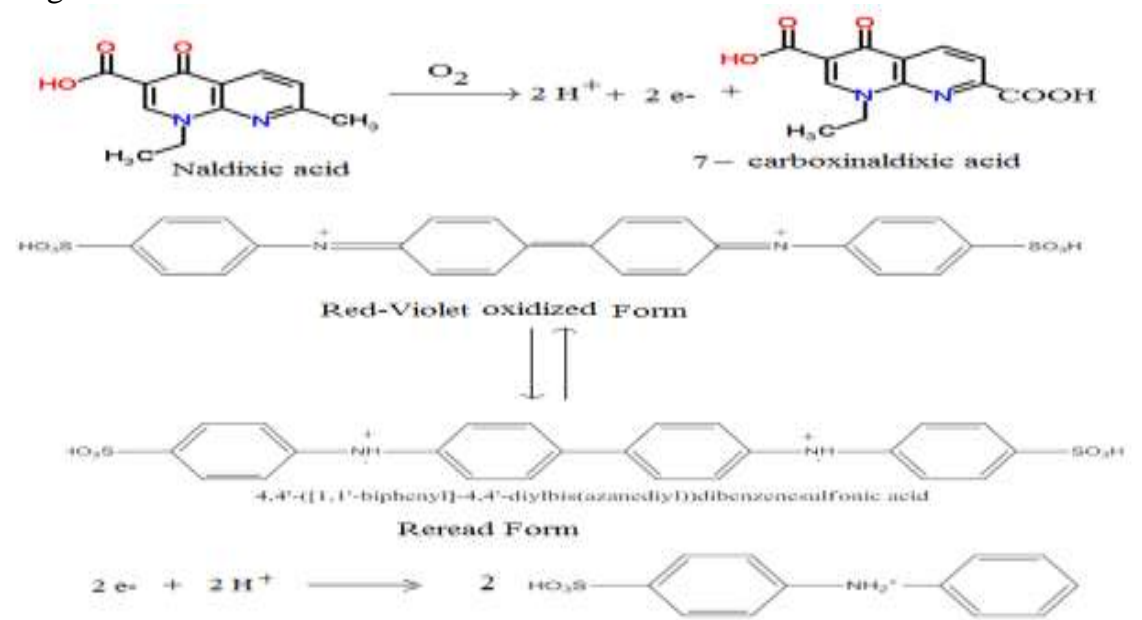

Scheme 1. The proposed redox reaction of DPAS oxidant and NA drug reductant in acid medium.

Effect of time

it was noticed that the violet reaction product formed between DPAS oxidized form indicator and the cited drug had been greatly affected by time where the violet colored products absorbance had been decayed with time and their spectra had been shifted into UV region as illustrated in Fig. 2 .

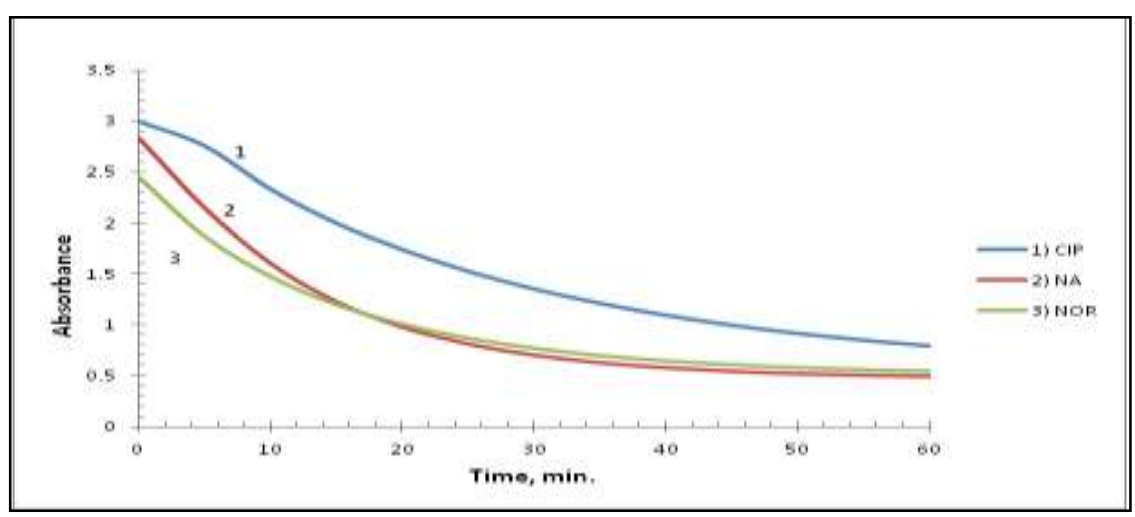

Fig. 2. Effect of time at normal temp and on the spectra of $4 \times 10^{-4} \mathrm{M}$ mixture of DPAS oxidant, with drug: 1) CIP (550nm), 2) NA (545nm), or 3) NOR (550nm) .

Egypt. J. Chem. 58, No. 3 (2015) 
This decay may be attributed to the change of DPAS from violet oxidized form into a brown reread form of $\lambda_{\max }$, studied in UV region.

Brown form and selection of suitable wavelengths

Spectral studies were carried out on the change of DPAS indicator into a brown reread form (curve 1) and its reaction with CIP (curve 2), NA (curve 3), and NOR (curve 4), as shown in Fig. 3.

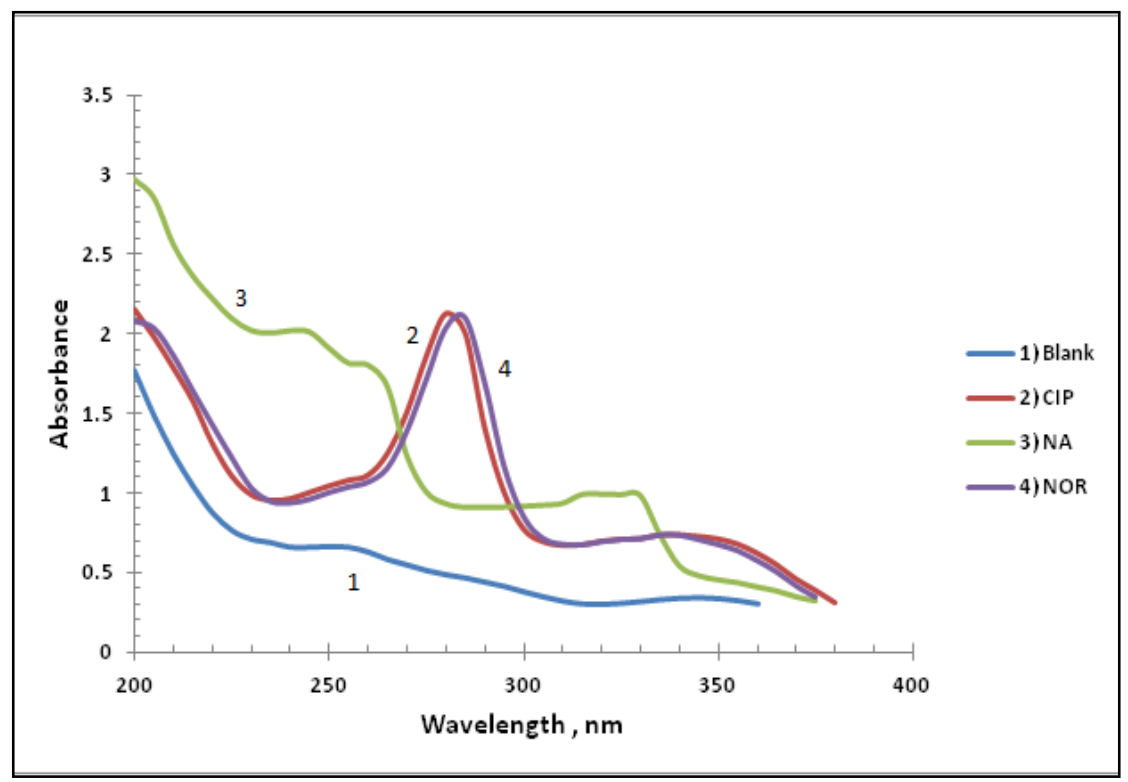

Fig. 3. UV spectra of $4 \times 10^{-5} \mathrm{M}$ DPAS oxidant indicator as a blank (curve 1) and $4 \mathrm{X10}^{-5} \mathrm{M}$ mixture of DPAS oxidant, with drug CIP, NA or NOR (curves 2-4) at normal temp. and after $30 \mathrm{~min}$.

It is obvious that the $\lambda_{\max }$ of DPAS indicator is shifted from $560 \mathrm{~nm}$ (violet form) (Fig. 1) to $250 \mathrm{~nm}$ (brown form). While the $\lambda_{\max }$ of the reaction products of the studied drugs with DPAS is shifted from 550, 545, $550 \mathrm{~nm}$ (violet form) (Fig. 1) to 280, 245, 285nm (brown form) for CIP, NA, and NOR, respectively. Also, it is obvious that DPAS has low intensity in the UV region compared to the drugs and the reaction under these conditions may take another way.

\section{Effect of temperature}

On studying the effect of temperature at different temperature region $(30-100$ $\left.{ }^{\circ} \mathrm{C}\right)$ gives the results in Fig. 4 . The violet reaction products between the cited drugs and DPAS oxidant indicator were highly sensitive to temperature change. These forms were changed into Brown Forms at high temperatures within few minutes instead of one hour at normal temperature. These forms changed their internal structures into the new stable forms; which were detected in UV region.

Egypt. J. Chem. 58, No. 3 (2015) 


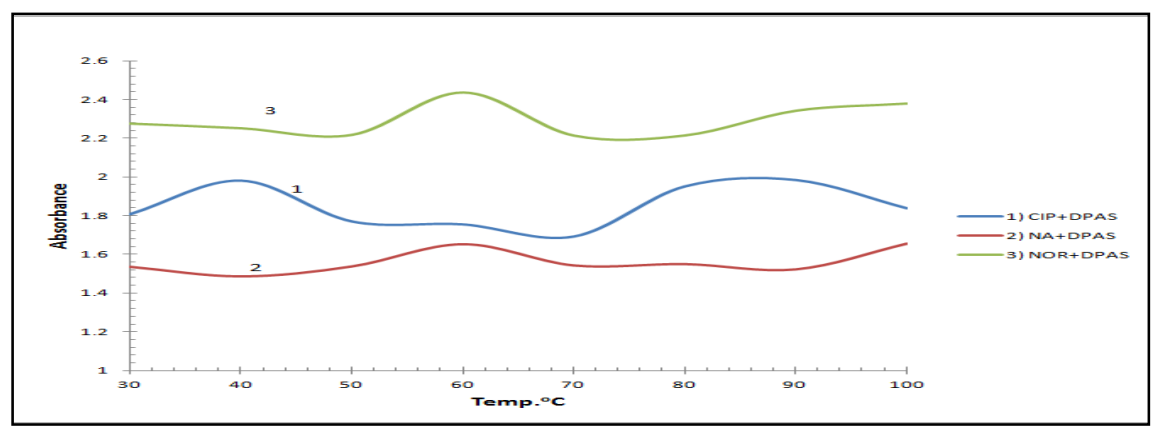

Fig. 4. Effect of temp. $\left(30-100^{\circ} \mathrm{C}\right)$ on spectra of $4 \times 10^{-5} \mathrm{M}$ mixture of DPAS oxidant with: 1) CIP (280 nm), 2) NA (245 nm), or 3) NOR (285 nm) after $30 \mathrm{~min}$.

Therefore it is possible to select $40^{\circ} \mathrm{C}$ for CIP and $60^{\circ} \mathrm{C}$ for both NA, NOR as suitable ones for using the studied drugs in micro-determination in the UV region.

\section{Stoichiometric ratio}

The nature of the binding of indicator in its reduced form to the drugs in its oxidized form is determined by Job's method of molar ratio method ${ }^{(36)}$ using constant reagent concentration of DPAS indicator and variable concentrations of CIP, NA and NOR (Fig. 5).

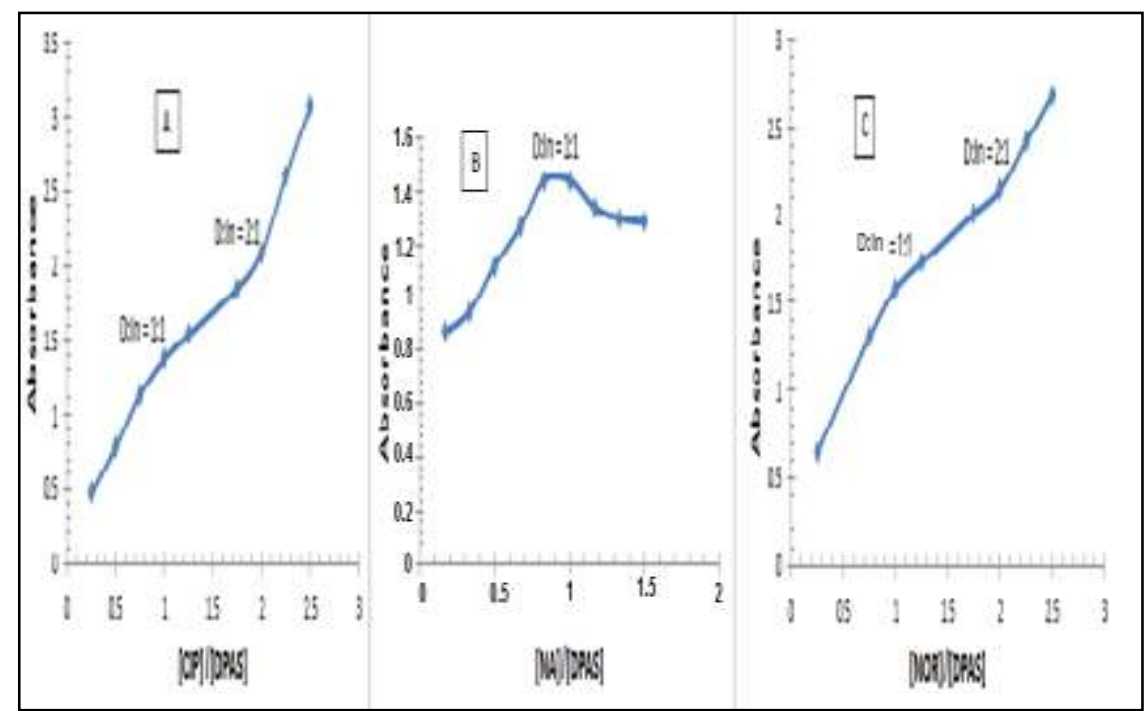

Fig. 5. Molar ratio of DPAS with different conc. of: A) CIP $\left(280 \mathrm{~nm}, 40^{\circ} \mathrm{C}\right)$, B) NA $\left(245 \mathrm{~nm}, 6^{\circ} \mathrm{C}\right)$, or C) NOR $\left(285 \mathrm{~nm}, 60^{\circ} \mathrm{C}\right)$. 
The results obtained in indicated that $1: 1$ and $2: 1$ ratio [drug]: [DPAS] ionpair is formed through the electrostatic attraction between positive protonated DPAS indicator and drug negative anion. Therefore; a proposal for the reaction mechanism taking Norfloxacin as an example is presented in Scheme 2.

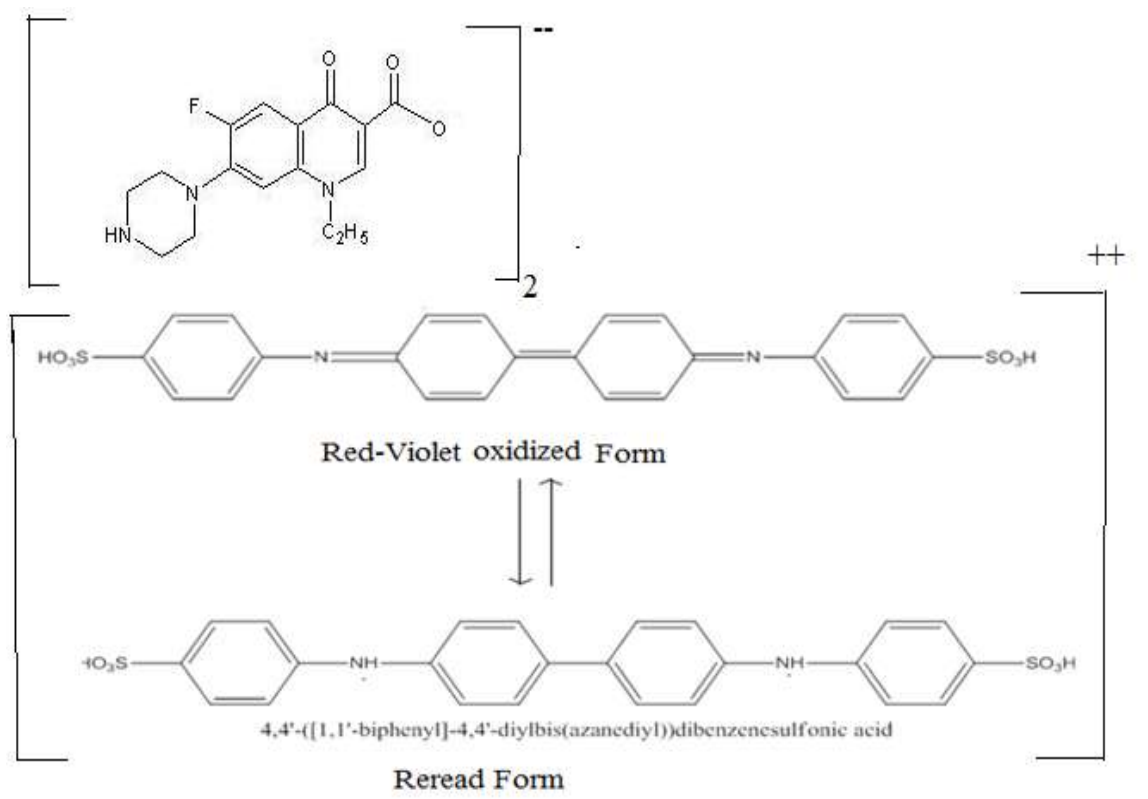

Scheme 2.The proposed reaction mechanism of DPAS oxidant and NOR drug via formation of ion-pair.

\section{Method validation}

Under the experimental conditions described above, Beer's law was valid over the concentration range $19.3-154.3,11.6-92.9$, and $15.9-127.7 \mu \mathrm{g} \mathrm{mL}^{-1}$ at violet form while $1.9-15.4,2.3-9.3$, and $1.6-12.7 \mu \mathrm{g} \mathrm{mL}^{-1}$ at brown form for CIP, NA, and NOR using DPAS oxidant, respectively. Table 1 shows the different analytical parameters obtained such as slope, intercept, correlation coefficient, Sandell sensitivity, molar absorpitivity (E), standard deviation, and relative standard deviation, limit of quantification and limit of detection.

It is obvious from Table 1, that the accuracy and precision of the proposed methods are indicated by the small values of SD and RSD. The calculated values of Sandell sensitivity (S.S) and Molar absorpitivity $(\varepsilon)$ confirm the sensitivity of the methods. The linearity of calibration graphs which are proved by the high values of the correlation coefficient $(r)$ and the small values of the $\gamma$-intercepts of the regression equations. The limits of detection (LOD) and quantitation (LOQ) values are explaining the validation of the proposed methods. 
TABLE 1. Analytical parameters for spectrophotometric determination of standard CIP, NA, and NOR drugs by the proposed DPAS methods .

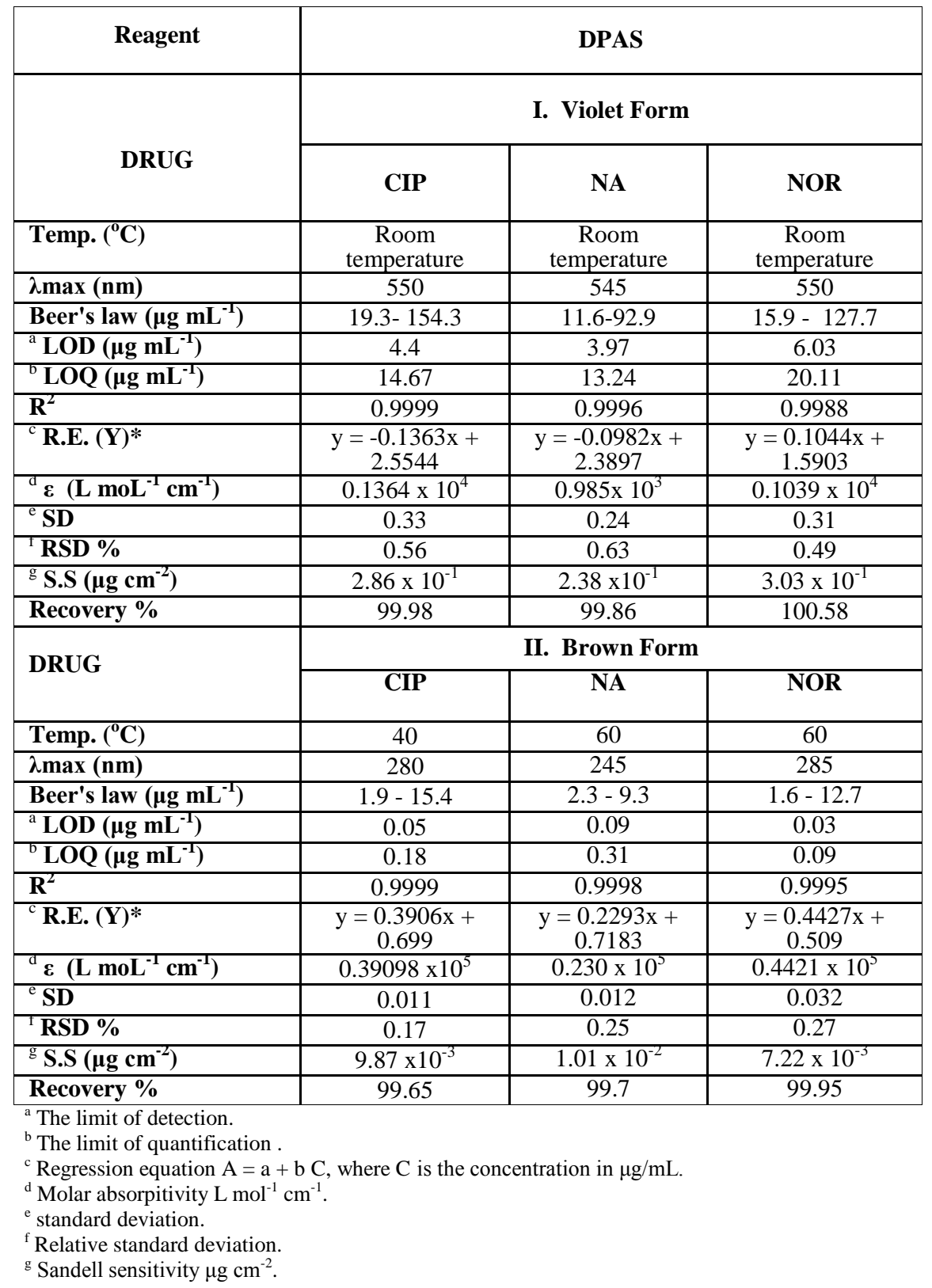


Inter- and intra-day study

Table 2 presents the precision of the proposed methods between the cited drugs and DPAS indicator at brown form through the Inter- and Intra- day measurements, confirming adequate sample stability and method reliability. This is because for the five selected concentrations within the linearity range, the observed RSDs were all $<1 \%$.

TABLE 2. Within-day and in between- days spectrophotometric microdetermination of standard CIP, NA, and NOR drugs by the proposed DPAS method at UV region (Brown Form) .

\begin{tabular}{|c|c|c|c|c|c|c|c|c|c|}
\hline \multirow[t]{2}{*}{ Drug } & \multirow{2}{*}{$\begin{array}{c}{[w t]} \\
\text { taken } \\
\left(\mu g \mathbf{~ m L}^{-1}\right)\end{array}$} & \multicolumn{2}{|c|}{$\begin{array}{c}\text { [wt] found } \\
\left(\mu \mathrm{g} \mathrm{mL} \mathbf{L}^{-1}\right)\end{array}$} & \multicolumn{2}{|c|}{ Recovery (\%) } & \multicolumn{2}{|c|}{ SD } & \multicolumn{2}{|c|}{$\operatorname{RSD}(\%)$} \\
\hline & & W-day & In- day & W-day & In- day & W-day ${ }^{a}$ & In- day ${ }^{b}$ & W-day ${ }^{a}$ & In- day ${ }^{b}$ \\
\hline \multirow{5}{*}{ CIP } & 3.86 & 3.85 & 3.85 & 99.79 & 99.79 & 0.03 & 0.033 & 0.82 & 0.88 \\
\hline & 4.82 & 4.79 & 4.79 & 99.33 & 99.32 & 0.038 & 0.035 & 0.79 & 0.72 \\
\hline & 8.60 & 8.68 & 8.68 & 100.89 & 100.9 & 0.068 & 0.065 & 0.78 & 0.75 \\
\hline & 10.61 & 10.67 & 10.65 & 100.57 & 100.38 & 0.05 & 0.045 & 0.47 & 0.42 \\
\hline & 12.54 & 12.53 & 12.57 & 99.93 & 100.25 & 0.05 & 0.04 & 0.42 & 0.32 \\
\hline \multirow{5}{*}{ NA } & 2.90 & 2.91 & 2.92 & 100.2 & 100.2 & 0.028 & 0.028 & 0.95 & 0.95 \\
\hline & 3.60 & 3.59 & 3.60 & 99.7 & 99.7 & 0.016 & 0.016 & 0.44 & 0.44 \\
\hline & 4.99 & 4.97 & 4.98 & 99.5 & 99.5 & 0.029 & 0.029 & 0.59 & 0.59 \\
\hline & 5.81 & 5.83 & 5.84 & 100.4 & 100.4 & 0.038 & 0.038 & 0.66 & 0.66 \\
\hline & 6.97 & 6.97 & 6.98 & 100.04 & 100.04 & 0.056 & 0.056 & 0.81 & 0.81 \\
\hline \multirow{5}{*}{ NOR } & 2.71 & 2.75 & 2.74 & 101.3 & 100.95 & 0.024 & 0.014 & 0.88 & 0.51 \\
\hline & 3.67 & 3.73 & 3.74 & 101.57 & 101.8 & 0.017 & 0.11 & 0.45 & 0.31 \\
\hline & 5.59 & 5.6 & 5.58 & 100.2 & 99.85 & 0.043 & 0.038 & 0.76 & 0.68 \\
\hline & 6.87 & 6.82 & 6.83 & 99.34 & 99.48 & 0.061 & 0.045 & 0.89 & 0.66 \\
\hline & 10.38 & 10.42 & 10.41 & 100.4 & 100.31 & 0.054 & 0.055 & 0.52 & 0.52 \\
\hline
\end{tabular}

${ }^{\mathrm{b}}$ Mean values for five replicates experiments at each concentration level at 5 days.

Egypt. J. Chem. 58, No. 3 (2015) 


\section{Applications}

The proposed methods were successfully applied to determine Ciprofloxacin, Nalidixic acid, and Norfloxacin in their commercial tablets. The commonly used excipients and additives in the preparation of tablets were found not to interfere in the analysis. The SD, \% recoveries, and statistical analysis regarding the calculated student's t-test and variance ratio F-test ${ }^{(38)}$ of the three drugs in their tablets compared with that of the official methods ${ }^{(6,28,37)}$ are given in Table 3, The values did not exceed the theoretical tabulated values indicating that there is no significant difference between the proposed and the official methods regarding accuracy and precision.

TABLE 3. Spectrophotometric micro - determination of CIP, NA, and NOR drugs in pharmaceutical Formulations by proposed DPAS method and official method .

\begin{tabular}{|c|c|c|c|c|c|c|c|c|c|c|c|c|}
\hline \multirow[b]{3}{*}{ Drug } & \multirow{2}{*}{\multicolumn{3}{|c|}{$\begin{array}{c}\text { Proposed Method } \\
\text { Violet Form } \\
\end{array}$}} & \multirow{2}{*}{\multicolumn{3}{|c|}{ Official Method }} & \multirow{2}{*}{\multicolumn{3}{|c|}{$\begin{array}{c}\text { Proposed Method } \\
\text { Brown Form } \\
\end{array}$}} & \multirow{2}{*}{\multicolumn{3}{|c|}{ Official Method }} \\
\hline & & & & & & & & & & & & \\
\hline & 跒 & 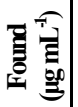 & 选 & 牙 & 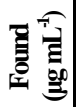 & 焉 & 昰 & 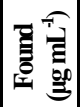 & 递 & 要 & 窝 & 焉 \\
\hline \multirow{5}{*}{$\begin{array}{l}\text { CIP in Ciprofar } \\
\text { Tablet }(500 \mathrm{mg} / \\
\text { Tablet) }\end{array}$} & 17.36 & 17.82 & 102.64 & 5 & 4.94 & 98.84 & 6.8 & 6.83 & 100.6 & 10 & 9.92 & 99.24 \\
\hline & 86.81 & 86.27 & 99.38 & 10 & 10.12 & 101.24 & 8.72 & 8.81 & 101.04 & 20 & 19.92 & 99.61 \\
\hline & 106.10 & 106.07 & 99.98 & 20 & 19.65 & 98.25 & 11.73 & 11.72 & 99.9 & 40 & \begin{tabular}{|l|}
40.10 \\
\end{tabular} & 100.25 \\
\hline & 121.53 & 122.08 & 100.46 & 40 & 40.62 & 101.54 & 12.65 & \begin{tabular}{|l|}
12.62 \\
\end{tabular} & 99.73 & 60 & \begin{tabular}{|l|}
59.87 \\
\end{tabular} & 99.78 \\
\hline & 150.46 & 153.08 & 101.74 & 50 & 49.90 & 99.80 & \begin{tabular}{|l|}
14.43 \\
\end{tabular} & 14.5 & 100.5 & 80 & \begin{tabular}{|l|}
80.36 \\
\end{tabular} & 100.45 \\
\hline Mean \pm SD & \multicolumn{3}{|c|}{$100.84 \pm 0.68$} & \multicolumn{3}{|c|}{$99.93 \pm 1.44$} & \multicolumn{3}{|c|}{$100.35 \pm 0.07$} & \multicolumn{3}{|c|}{$99.87 \pm 0.49$} \\
\hline F-test & \multicolumn{3}{|c|}{$4.48(6.39) * * *$} & & & & & & & & & \\
\hline t-test & \multicolumn{3}{|c|}{$1.28(2.45)^{* * *}$} & & & & & & & & & \\
\hline \multirow{5}{*}{$\begin{array}{l}\text { NA in Nalidram } \\
\text { Tablet }(500 \mathrm{mg} / \\
\text { Tablet) }\end{array}$} & 29.03 & 29.26 & 100.8 & & & & 1.74 & 1.77 & \begin{tabular}{|l|}
101.6 \\
\end{tabular} & & & \\
\hline & 40.64 & 40.11 & 98.7 & & & & 3.02 & 2.98 & 98.7 & & & \\
\hline & 46.45 & 46.71 & 100.6 & 30 & \begin{tabular}{l|l}
30.15 \\
\end{tabular} & 100.49 & 4.06 & 4.03 & 99.2 & 30 & 30.15 & 100.49 \\
\hline & 52.25 & 51.89 & 99.03 & & & & 5.81 & 5.82 & 100.2 & & & \\
\hline & 81.28 & 81.65 & 100.45 & & & & 7.55 & 7.56 & 100.2 & & & \\
\hline Mean \pm SD & \multicolumn{3}{|c|}{$99.92 \pm 0.49$} & \multicolumn{3}{|c|}{$100.49 \pm 0.46$} & \multicolumn{3}{|c|}{$99.98 \pm 0.024$} & \multicolumn{3}{|c|}{$100.49 \pm 0.46$} \\
\hline F-test & \multicolumn{3}{|c|}{$1.13(6.39)^{* * *}$} & & & & & & & & & \\
\hline t-test & \multicolumn{3}{|c|}{$1.89(2.31)^{* * *}$} & & & & & & & & & \\
\hline \multirow{5}{*}{$\begin{array}{l}\text { NOR in Norbactin } \\
\text { Tablet (400 mg / } \\
\text { Tablet) }\end{array}$} & 39.92 & 39.6 & 99.2 & 20 & \begin{tabular}{ll|}
19.74 \\
\end{tabular} & 98.70 & 2.39 & 2.41 & \begin{tabular}{|l|}
100.63 \\
\end{tabular} & 10 & 10.04 & 100.41 \\
\hline & 55.88 & 55.8 & 99.9 & 40 & 40.76 & 101.91 & 3.99 & 4.03 & 100.96 & 20 & \begin{tabular}{|l|}
19.88 \\
\end{tabular} & 99.38 \\
\hline & 63.87 & |63.99 & 100.2 & 80 & 78.85 & 98.57 & 7.18 & 7.12 & \begin{tabular}{|l|}
99.09 \\
\end{tabular} & 40 & 40.04 & 100.11 \\
\hline & 71.85 & 72.8 & 101.3 & 120 & 120.09 & 100.07 & 8.78 & 8.8 & 100.21 & 60 & \begin{tabular}{|l|}
60.27 \\
\end{tabular} & 100.45 \\
\hline & 95.80 & 95.83 & 100.03 & 240 & 242.99 & 101.25 & 9.58 & 9.49 & \begin{tabular}{|l|}
99.06 \\
\end{tabular} & 80 & 80.06 & 101.08 \\
\hline Mean \pm SD & \multicolumn{3}{|c|}{$100.13 \pm 0.60$} & \multicolumn{3}{|c|}{$100.10 \pm 1.49$} & \multicolumn{3}{|c|}{$99.99 \pm 0.041$} & \multicolumn{3}{|c|}{$100.09 \pm 0.43$} \\
\hline F-test & \multicolumn{3}{|c|}{$6.17(6.39) * * *$} & & & & & & & & & \\
\hline t-test & \multicolumn{3}{|c|}{$0.04(2.57) * * *$} & & & & & & & & & \\
\hline
\end{tabular}

Egypt. J. Chem. 58, No. 3 (2015) 


\section{Conclusion}

In this study, DPAS is used as an oxidant spectrophotometric selfindicator for the first time. The proposed methods described are simple, reliable, sensitive and efficient for routine analysis of this class of antibiotics in raw materials and pharmaceutical dosage over a wide concentration range without interference from common excipients. In addition, the methods can use spectrophotometric at both UV and Visible regions. Moreover, they involve the advantage of the use of inexpensive instrument without losing accuracy. Therefore, the methods are useful for applying the investigated drugs in bulk as well as in their tablets with high precision and good accuracy.

\section{References}

1. Reynolds, J.E.F. and Martindale, Ed, The Extra Pharmacopeia, $30^{\text {th }}$ ed. The Pharmaceutical Press London. (1993).

2. United States Pharmacopoeia XXV, National Formulary XX, US Pharmacopoeial Convention: Rockville, MD. (2002).

3. The British Pharmacopoeia, HMSO, London. (1998).

4. Rizk, M., Belal, F., Ibrahim, F., Ahmad, S.M. and El-Enany, N.M., A Simple kinetic spectrophotometric method for the determination of certain 4 quinolones in drug formulations. Sci. Pharm. 68(1), 173-188 (2000).

5. El-Brashy, A.M., El-Sayed, M.M. and El-Sepai, F.A., Spectrophotometric determination of some fluoroquinolone antibacterials by binary complex formation with Xanthene dyes. Farmaco. 59(10), 809-17 (2004).

6. El-Brashy, A.M., Metwally, M.E. and El-Sepai, F.A., Spectrophotometric determination of some fluoroquinolones antibacterials by ion-pair complex formation with cobalt (II) tetrathiocyanate. J. Chinese Chem. Soc. 52(1), 77-84 (2005).

7. Patel, M.N., Bhatt, B.S., Gandhi, D.S., Dosi, P.A. and Parmar, P.A., Spectrophotometric determination of ciprofloxacin by ion pair formation. J. Anal. Chem. 67(7), 655-660 (2012).

8. Chaple, D.R. and Bhusari, K.P., Spectrophotometric estimation of fluoroquinolones as ion-pairs with bromocresol green in bulk and pharmaceutical dosage form. Asian J. Chem. 22(4), 2593-2598 (2010).

9. El-Brashy, A.M., Metwally, M.E. and El-Sepai, F.A., Spectrophotometric determination of some fluoroquinolone antibacterials through charge-transfer and ion-pair complexation reactions. Bull. Korean Chem. Soc. 25(3), 365-372 (2004). 
10. Mostafa, S., El-Sadek, M. and Alla E.A., Spectrophotometric determination of ciprofloxacin, enrofloxacin and pefloxacin through charge transfer complex formation. J. Pharm. Biomed. Anal. 27(1-2), 133-142 (2002).

11. Djurdjević, P., Todorović, M., Stankov, M.J. and Odović, J., Spectrophotometry determination of ciprofloxacin in serum using iron(iii) ion as chromogenic agent. Anal. Lett. 33(4), 657-665 (2000).

12. Khedr, A.M., Gaber, M. and El-Kady, A.S., Spectrophotometric determination of norfloxacin in pure and dosage forms by complexation with $\mathrm{Fe}(\mathrm{III})$ and $\mathrm{Cu}(\mathrm{II})$ Ions. I.R.J.P.P. 2(5), 97-102 (2012).

13. Nagaralli, B.S., Seetharamappa, J. and Melwanki, M.B., Sensitive spectrophotometric methods for the determination of amoxicillin, ciprofloxacin and piroxicam in pure and pharmaceutical formulations. J. Pharm. Biomed. Anal. 29(5), 859-864 (2002).

14. Thabaj, K.A., Kulkarni, S.D., Chimatadar, S.A. and Nandibewoor, S.T., Oxidative transformation of ciprofloxacin by alkaline permanganate - A kinetic and mechanistic study. Polyhedron. 26(17), 4877-4885 ( 2007).

15. Naik, P.N., Chimatadar, S.A. and Nandibewoor, S.T., Kinetics and oxidation of fluoroquinolone antibacterial agent, norfloxacin, by alkaline permanganate: A mechanistic study. Ind. Eng. Chem. Res. 48(5), 2548-2555 (2009).

16. Singh, S., Inamullah, Sharma, S., Yadav, A.K. and Gautam, H., Estimation of Norfloxacin in tablet dosage form by using UV-Vis Spectrophotometer. Der. Pharmacia. Lettre. 4(6), 1837-1842 (2013).

17. Hopkala, H. and Kowalczuk, D., Application of derivative UV Spectrophotometry for the determination of Enoxacin and Nalidixic acid in tablets. Pharmazie. 55(6), 432-435 (2000).

18. Rizk, M.S., Belal, F., Ibrahim, F.A., Ahmad, S.M. and Sheribah, Z.A., Derivative spectrophotometric analysis of some 4-quinolone antibacterials in formulations and spiked biological fluids via their $\mathrm{Cu}$ (II)-complexes. J. Assoc. Off. Anal. Chem. Int. 84(2), 368-375 (2001).

19. Mandil, H., Sakur, A.A. and Nasse, B., Potentiometric determination of Gatifloxacin \& Ciprofloxacin in pharmaceutical formulations. Int. J. Pharm. Sci. 4(4), 537-542 (2012).

20. Bhardwaj, N., Complexation of Ciprofloxacin with Mn (II) Ion -A Potentiometric Study. Orient. J. Chem. 29(3), 1179-1181 (2013).

21. Park, H.R., Chung, K.Y., Lee, H.C., Lee, J.K. and Bark, K.M., Ionization and divalent cation complexation of quinolone antibiotics in aqueous solution. Bull. Korean Chem. Soc. 21 (9), 849-854 (2000).

22. Maheshwari, R.K., Chaturvedi, S.C. and Jain, N.K., Novel spectrophotometric estimation of some poorly water soluble drugs using hydrotropic solubilizing agents. Indian. J. Pharm. Sci. 68(2), 195-198 (2006). 
23. Mandil, H., Sakur, A.A. and Nasser, B., Use of Cerium (IV) in Potentiometric titration of norfloxacin in pharmaceutical preparations. Asian J. Chem. 24(7), 29852988 (2012).

24. Ghoneima, M.M., Radic, A. and Beltagib, A.M., Determination of norfloxacin by square-wave adsorptive voltammetry on a glassy carbon electrode. J. Pharmaceut. Biomed. 25 (2), 205-210 (2001).

25. Basavaiah, K., Nagegowda, P., Somashekar, B.C. and Ramakrishna, V., Spectrophotometric and titrimetric determination of ciprofloxacin based on reaction with Cerium (IV) Sulphate. Science Asia. 32(4), 403-409 (2006).

26. Ebeshi, B.U, Vaikosen, E. and Komonibo, P.W., Simple and cost-effective spectrophotometric and titrimetric methods for the determination of Ciprofloxacin in tablets. Int. J. Biol. Chem. Sci. 5(1), 28-37 (2011).

27. Belal, F., Rizk, M., Aly, F.A. and El-Enany, N.M., Conductometric determination of some pharmaceutically important 4-quinolone derivatives in dosage forms. Chem. Anal. 44(4), 763-772 (1999).

28. El-Brashy, A. M., Metwally, M. and El-Sepai, F. A., Spectrophotometric and atomic absorption spectroscopic determination of some fluoroquinolone antibacterials by ion-pair complex formation with Bismuth (III) Tetraiodide. $J$. Chinese Chem. Soc. 52(2), 253-262 (2005).

29. Wang, M.L., Chen, S.C., Lien, J.C. and Kuo, S.C., Determination of Nalidixic acid by fluorimetry with Sodium Borohydride and Hydrogen Peroxide. J AOAC Int. 85(3), 572-575 (2002).

30. Nandipati, S., Vanka, K.R. and Uba, S., The separation and quantitative determination of ciprofloxacin in a pharmaceutical formulation by ultra performance liquid chromatography. Int. J. Pharm. Sci. 5(3), 312-317 (2013).

31. Borrego, M.C., Díaz, M.C. and Díaz, D.C., Validation of a high-performance liquid chromatographic method for the determination of Norfloxacin and its application to stability studies (photo-stability study of Norfloxacin). J. Pharmaceut. Biomed. 18(6), 919-926 (1999).

32. Shargel, L., Koss, R.F., Crain, A.V.R. and Boyle, V.J., Nalidixic acid and Hydroxy Nalidixic acid analysis in human plasma and urine by liquid chromatography. J. Pharm. Sci. 62 (9), 1452-1454 (1973).

33. Sorel, R.H.A., Hulshoff, A. and Snelleman, C., High-Performance Liquid Chromatographic analysis of nalidixic acid and hydroxy nalidixic acid in plasma with a dynamic anion-exchange system. J. Chromatogr. 221(1), 129-137 (1980).

34. Wu, S.M., Wu, H.L. and Hwei, S., Derivatization-gas chromatographic analysis of nalidixic acid in tablets. J. Chin. Chem. Soc. 34(1), 7-11 (1987). 
35. Hulanicki, A. and Glab, S., Redox Indicators. Characteristics and Applications. Pergamon Press. 50, 463-498 (1978).

36. Job, P., Spectrochemical Methods of Analysis. WileyIntersience, New York. p 346 (1971).

37. Shervington, L.A., Abba, M., Hussain, B. and Donnelly, J., The Simultaneous separation and determination of five quinolone antibotics using isocratic reversedphase HPLC: Application to stability studies on an ofloxacin tablet formulation. $J$. Pharm. Biomed. Anal. 39(3-4), 769-775 (2005).

38. Fritz, J.S. and Schenk, G.H., Quantitative Analytical Chemistry, $4^{\text {th }}$ ed. Allyn and Bacon, Inc, Boston. (1979).

(Received $14 / 12 / 2014$ accepted 25/3/2015)

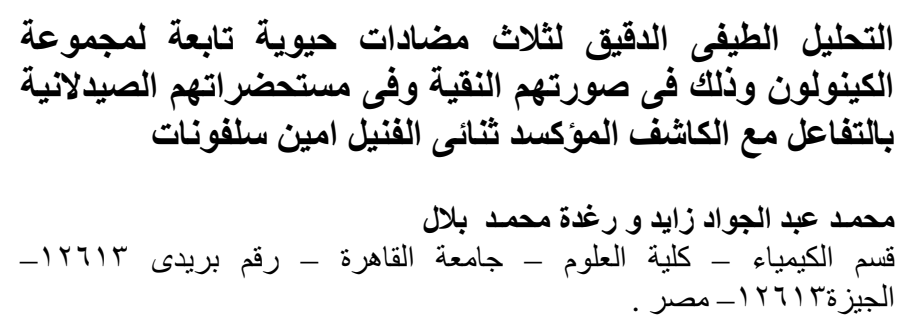

يقوم هذا البحث بدراسة طرق طيفية جديدة وفعالة بالاضافة لحساسيتها لتعيين

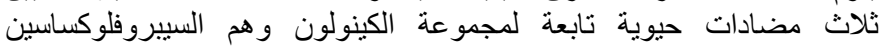

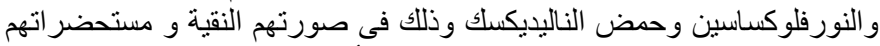

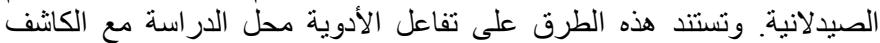

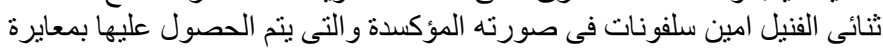

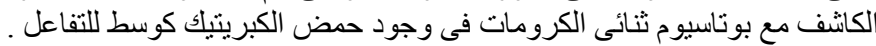

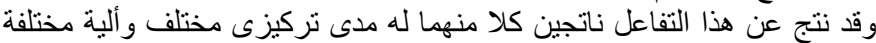

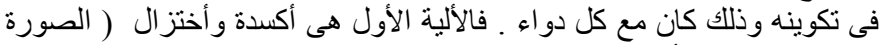

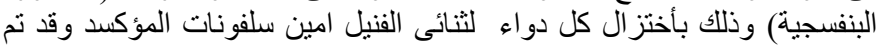

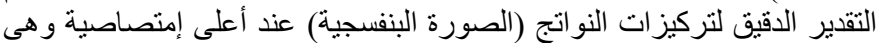

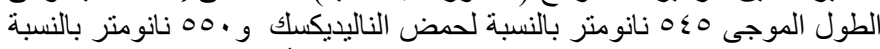

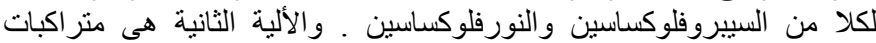

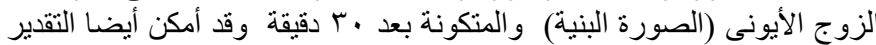
الاقيق لتركيزات النواتج (الصورة النورة والبنية)

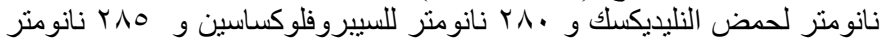

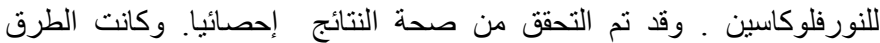

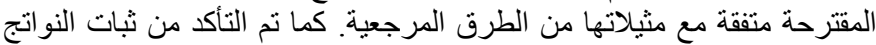

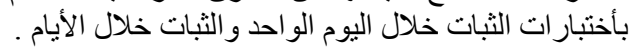

